\title{
Influence of gender on psychomotor vigilance task performance by adolescents
}

\author{
F. Beijamini, A.G.T. Silva, C.A.T. Peixoto and F.M. Louzada \\ Laboratório de Cronobiologia Humana, Departamento de Fisiologia, Setor de Ciências Biológicas, \\ Universidade Federal do Paraná, Centro Politécnico, Curitiba, PR, Brasil \\ Correspondence to: F. Beijamini, Laboratório de Cronobiologia Humana, Departamento de Fisiologia, \\ Setor de Ciências Biológicas, Universidade Federal do Paraná, Centro Politécnico, 81531-990 Curitiba, \\ PR, Brasil \\ Fax: +55-41-3361-1414. E-mail: beijamini@gmail.com
}

\begin{abstract}
During adolescence, the sleep phase delay associated with early school times increases daytime sleepiness and reduces psychomotor performance. Some studies have shown an effect of gender on psychomotor performance in adults and children. Males present faster reaction times (RT) compared with females. The aim of the present study was to evaluate the influence of gender on Palm psychomotor vigilance task (PVT) performance in adolescents. Thirty-four adolescents (19 girls, 13 to 16 years old) attending morning school classes of a public school in Curitiba, PR, Brazil, participated in the study. Sleep patterns were measured using actigraphy and sleepiness data were accessed with the Karolinska Sleepiness Scale (KSS). KSS and PVT measurements were collected at two times in the morning (8:00 and 11:00 h). The data were compared using one-way ANOVA, considering gender as a factor. ANOVA indicated that gender did not affect sleep patterns and subjective somnolence; however, a statistically significant effect of gender was detected for PVT performance. Boys presented faster RT (RT-PVT1: 345.51 ms, $\mathrm{F}=6.08, \mathrm{P}<0.05$; RT-PVT2: $343.30 \mathrm{~ms}, \mathrm{~F}=6.35, \mathrm{P}<0.05$ ) and fewer lapses (lapses-PVT1: 8.71, $\mathrm{F}=4.45, \mathrm{P}<0.05$; lapsesPVT2: 7.82, $F=7.06, P<0.05$ ) compared with girls (RT-PVT1: 402.96; RT-PVT2: 415.70; lapses-PVT1: 16.33; lapses-PVT2: 17.80). These results showed that this effect of gender, already reported in adults and children, is also observed in adolescents. The influence of gender should be taken into account in studies that use Palm PVT to evaluate psychomotor performance in this age range.
\end{abstract}

Key words: Sleep/wake cycle; Karolinska Sleepiness Scale performance; Adolescent; Gender; Psychomotor vigilance task

Presented at the XI Congresso Brasileiro do Sono. Fortaleza, CE, Brazil, November 11-14, 2007.

Received November 5, 2007. Accepted July 17, 2008

\section{Introduction}

Sleep/wake cycle patterns change throughout development. Adolescents, individuals in the transitional stage of physical and mental human development that occurs between childhood and adulthood, tend to go to bed and get up later (1-4). This phase delay, in addition to early school starting times, reduces sleep duration and increases daytime sleepiness levels on weekdays (5-7), with an impact on school performance $(6,8)$.

Recently, more interventions are focusing on reducing the consequences of sleep phase delay. Some of these interventions are related to changes in school schedules while others focus on changes in sleep habits; they are generically called sleep education programs $(9,10)$. Results of these programs have shown an improvement in sleep habits, sleep quality and students knowledge about sleep $(9,10)$. Nevertheless, few studies have evaluated the impact of such programs on sleep patterns and have obtained only subjective sleep parameters in the analysis.

Subjective sleepiness and sustained attention are parameters that are altered in situations of partial sleep deprivation (11). The first can be measured by means of the Karolinska Sleepiness Scale (KSS) $(12,13)$. The psychomotor vigilance task (PVT) $(14,15)$ has been used in sleep research as an objective measure for the assessment of sustained attention and alertness. PVT results throughout the day reflect a circadian modulation of neuro- 
behavioral functions as well as the effect of sleep pressure developing with time awake (16-20).

Few studies have evaluated PVT performance in children and adolescents $(21,22)$. PVT is based on simple visual reaction time (RT), a response given to a circle presented briefly on a Palm LCD screen. The Palm PVT version of the task is designed to be used in field studies (23). Venker and colleagues (21), in a study with children 6-11 years of age, showed that RTs of boys were faster than those of girls. This gender difference tends to disappear when older children are compared (21). Blatter and colleagues (18) reported significantly slower RTs in women compared to men, both in young adults (20 to 31 years) and in healthy elderly individuals (57 to 74 years). A study that used a 2-and 4-choice task showed significantly faster RTs in men than in women. The authors suggested that this difference is caused by different strategies adopted by both genders to achieve optimal results when performing the PVT; in women by avoiding anticipations (accuracy) and in men by being as fast as possible (quickness) (24).

In recent years, we have developed interventions to reduce diurnal sleepiness and increase performance in adolescents and have investigated evaluation tools and factors related to intervention results. The objective of the present study was to investigate gender differences on PVT performance in adolescents.

\section{Subjects and Methods}

\section{Participants}

A group of 34 adolescents, 19 girls and 15 boys, 13 to 16 years of age (mean: $13.76 \pm 0.81$ years), who attended school in the morning (7:30 to $11: 45 \mathrm{am}$ ) at a public school in Curitiba, PR, in southern Brazil, participated in the study. There was no statistical difference between the average age of the girls and boys $(F=0.14, P=0.71$; ANOVA). The adolescents were healthy, did not present sleep disturbances and did not use medication related to the sleep/ wake cycle. The adolescents were not asked to follow fixed bedtime or wake-up schedules and they were allowed to drink coffee/caffeinated beverages during this time. The time spent going from home to school was 10-30 min. The adolescents' parents were informed of the study recommendations by the subjects.

\section{Procedures and Instruments}

The study conformed to international ethical standards based on the Declaration of Helsinki (25) and was approved by the Research and Ethics Committee of the Biological Sciences Institute of the Federal University of Paraná. The parents provided written informed consent.
The adolescents completed a sleep log and wore an activity monitor (Mini-Motionlogger, Zero crossing mode, Ambulatory Monitoring Inc., USA) on their non-dominant wrist during 5 consecutive days ( 3 weekdays and 2 weekend days) to record activity levels at 1-min intervals. The actigraph data were analyzed by a software program (Action-W) for measurement of sleep onset time, sleep offset time, and the duration of nocturnal sleep. The bedtime and wake time from subject's sleep log were used to guide analysis of the actigraph data recordings. For each sleep variable, two-way ANOVA was used with gender and day (weekdays and weekend days) as factors. The adolescents performed a 5-min Palm version of the PVT (16) and answered the KSS $(23,24)$. Both the PVT and KSS measures were completed twice in the morning (8:00 and 11:00 h) on 3 weekdays. For PVT data collection and filling in of the KSS, the adolescents went to a test room in groups of 5 to 8 subjects each time. In order to avoid any kind of interaction, the adolescents were separated physically in this room.

When performing the PVT, subjects were required to respond to a visual stimulus by pressing a pushbutton as soon as the stimulus appeared. They were instructed that speed and accuracy performance were equally important on all tasks. In this study, the duration of a single Palm PVT session lasted 5 min or until 100 stimuli were presented. Inter-stimulus intervals varied randomly from 1 to $5 \mathrm{~s}$. For each test, means were obtained for the following variables from the PVT data: RTs, anticipations and lapses. Anticipations were defined as responses made during the interstimulus interval before the next stimulus was presented or as an RT that was virtually impossible ( $<100 \mathrm{~ms})$. Lapses were defined as any reaction time $>500 \mathrm{~ms}$. PVT variable comparisons were carried out by three-way ANOVA (day, gender and time of the day as factors). Three-day means for reaction times, anticipations and lapses for each time of the day were compared by one-way ANOVA with gender as a factor. Before each individual PVT, sleepiness was assessed using the KSS that ranges from 1 to 9 , in which $1=$ very alert and $9=$ very sleepy (26). Three-day means for each time of the day (KSS1 and KSS2) were obtained. Due the non-normal distribution of the data, comparisons were carried out with the Mann-Whitney U-test with gender as a factor. The software used was Statistica (version 7.0, StatSoft, Inc., USA).

\section{Results}

The results of sleep patterns estimated from actigraphy are reported in Table 1. There was no effect of gender on sleep patterns (ANOVA). There was, however, an effect of 
day of the week on sleep patterns. Boys and girls slept more and showed a delay on sleep onset and offset on weekends compared with weekdays.

There was no effect of day or time of day on results. Sleepiness was not affected by gender.

There was no effect of day or time of day on RTs. Gender had a significant effect on mean RT at both PVT times: PVT1 ( $F=6.08$, $\mathrm{P}<0.05$, ANOVA) and PVT2 $(\mathrm{F}=6.35, \mathrm{P}<$ 0.05). Results are shown in Figure 1. The RTs of the boys were faster than those of the girls.

There were statistically significant gender differences in lapses. Boys had fewer lapses compared to girls for both PVT times: PVT1 (F $=4.45, \mathrm{P}<0.05$, ANOVA) and PVT2 ( $=7.06, \mathrm{P}<0.05)$. Anticipations were not significantly affected by gender (ANOVA; Table 2).

\section{Discussion}

Our results showed an influence of gender on PVT performance in adolescents. The relationship between sleep reduction and performance is well known $(19,26,27)$. In our study, boys and girls showed similar sleep patterns and subjective sleepiness measured by KSS. Differences in these variables could explain, at least in part, differences detected in PVT performance.

Actually, these differences in reaction times seem to be normal between genders and have already been observed in children and adults $(18,21,28)$. It is known that boys and girls perform differently on cognitive tests $(18,29)$. Many studies have used performance tasks such as PVT and other reaction time tasks to investigate the effect of sleep restriction in children $(30,31)$. Recently, Crowley and Carskadon (32) reported the use of a personal digital assistant PVT in adolescents. However, they did not investigate the influence of gender. Nevertheless, as far as we know, our study is the first report of such influence on this age range on Palm PVT performance.

One of the reasons for this difference could be that girls adopt different strategies for test resolution, presenting fewer anticipations than boys, indicating accuracy $(21,26)$. However, our results do not corroborate the hypothesis of adoption of different strategies between genders as girls did not show fewer anticipations compared with boys.

This study showed differences between adolescent males and females in PVT performance, confirming a tendency throughout development since there is prior evidence in studies carried out with other age groups
Table 2. Anticipations and lapses by gender using the psychomotor vigilance task (PVT).

\begin{tabular}{lcc}
\hline & Boys $(\mathrm{N}=15)$ & Girls $(\mathrm{N}=19)$ \\
\hline Mean antecipations & & \\
PVT1 & $4.71 \pm 4.40$ & $6.58 \pm 5.19$ \\
PVT2 & $4.98 \pm 6.37$ & $7.28 \pm 8.12$ \\
Mean lapses & & \\
PVT1 & $8.71 \pm 7.80$ & $16.33 \pm 12.13^{\mathrm{a}}$ \\
PVT2 & $7.82 \pm 7.42$ & $17.81 \pm 12.93^{\mathrm{b}}$ \\
\hline
\end{tabular}

Data are reported as means \pm SD. Tests were performed at 8 (PVT1) and 11 am (PVT2).

aP $<0.05$ compared to PVT1 by boys; bP $<0.05$ compared to PVT2 by boys.

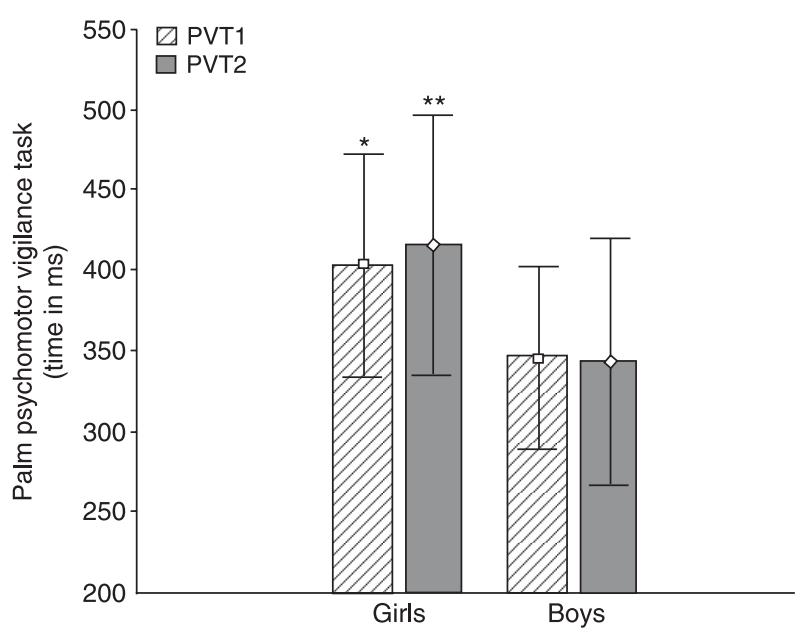

Figure 1. Reaction time by gender evaluated by the psychomotor vigilance task (PVT). Data are reported as means $\pm S D$. PVT1 refers to tests performed at 8 am and PVT2 refers to tests performed at $11 \mathrm{am}$. ${ }^{*} \mathrm{P}<0.05$ compared to PVT1 by boys and ${ }^{* *} \mathrm{P}<0.05$ compared to PVT2 by boys. 
$(18,21,24)$. One could speculate how much the toys utilized during childhood might be capable of influencing adolescent performance on the PVT. Our results show that gender is a factor that has to be taken into account in studies that evaluate reaction times.

Adolescents are more susceptible to sleep deprivation due to the combination of sleep phase delay and morning school schedules. For this reason, the development of tools to objectively evaluate the consequences of sleep deprivation and the effects of sleep education programs in this age range is required. The Palm version of the PVT seems to be a good alternative for evaluating sustained

\section{References}

1. Carskadon MA, Vieira C, Acebo C. Association between puberty and delayed phase preference. Sleep 1993; 16: 258-262.

2. Andrade MM, Benedito-Silva AA, Domenice S, Arnhold IJ, Menna-Barreto L. Sleep characteristics of adolescents: a longitudinal study. J Adolesc Health 1993; 14: 401-406.

3. Louzada F, Menna-Barreto L. Sleep-wake cycle expression in adolescence: influences of social context. Biol Rhythm Res 2003; 34: 129-136.

4. Van den Bulck J. Television viewing, computer game playing, and Internet use and self-reported time to bed and time out of bed in secondary-school children. Sleep 2004; 27: 101-104.

5. Lima PF, Medeiros AL, Araujo JF. Sleep-wake pattern of medical students: early versus late class starting time. Braz J Med Biol Res 2002; 35: 1373-1377.

6. Wolfson AR, Carskadon MA. Understanding adolescents' sleep patterns and school performance: a critical appraisal. Sleep Med Rev 2003; 7: 491-506.

7. Mello L, Louzada F, Menna-Barreto L. Effects of school schedule transition on sleep-wake cycle of Brazilian adolescents. Sleep Hypnosis 2001; 3: 3.

8. Crowley SJ, Acebo C, Carskadon MA. Sleep, circadian rhythms, and delayed phase in adolescence. Sleep Med 2007; 8: 602-612.

9. Brown FC, Buboltz WC Jr, Soper B. Development and evaluation of the Sleep Treatment and Education Program for Students (STEPS). J Am Coll Health 2006; 54: 231-237.

10. Cortesi F, Giannotti F, Sebastiani T, Bruni O, Ottaviano S. Knowledge of sleep in Italian high school students: pilot-test of a school-based sleep educational program. J Adolesc Health 2004; 34: 344-351.

11. Kaida K, Takahashi M, Akerstedt $T$, Nakata A, Otsuka $Y$, Haratani $T$, et al. Validation of the Karolinska sleepiness scale against performance and EEG variables. Clin Neurophysiol 2006; 117: 1574-1581.

12. Akerstedt T, Gillberg M. Subjective and objective sleepiness in the active individual. Int $J$ Neurosci 1990; 52: 29-37.

13. Teixeira LR, Lowden A, Turte SL, Nagai R, Moreno CR, Latorre MR, et al. Sleep and sleepiness among working and attention in field studies and a tool to detect the effect of sleep education programs on adolescent sleep patterns. For this reason it is important to identify factors that interfere with PVT performance, such as the effect of gender observed in this study.

Our results do not permit the identification of the causes of these differences, which could be explained by genderintrinsic characteristics and their consequent physiological and anatomic differences. Further studies are required to investigate the responsible inherent mechanisms related to the difference found between genders.

non-working high school evening students. Chronobiol Int 2007; 24: 99-113.

14. Wilkinson RT, Houghton D. Field test of arousal: a portable reaction timer with data storage. Hum Factors 1982; 24 : 487-493.

15. Dinges $D$, Powell J. Microcomputer analyses of performance on a portable, simple RT task during sustained operations. Behav Res Methods Instrum Comput 1985; 17: 652-868.

16. Loh S, Lamond N, Dorrian J, Roach G, Dawson D. The validity of psychomotor vigilance tasks of less than 10minute duration. Behav Res Methods Instrum Comput 2004; 36: 339-346.

17. Parasuraman R, Nestor P, Greenwood P. Sustained-attention capacity in young and older adults. Psychol Aging 1989; 4: $339-345$

18. Blatter K, Graw P, Munch M, Knoblauch V, Wirz-Justice A, Cajochen $C$. Gender and age differences in psychomotor vigilance performance under differential sleep pressure conditions. Behav Brain Res 2006; 168: 312-317.

19. Dinges DF, Pack F, Williams K, Gillen KA, Powell JW, Ott $\mathrm{GE}$, et al. Cumulative sleepiness, mood disturbance, and psychomotor vigilance performance decrements during a week of sleep restricted to $4-5$ hours per night. Sleep 1997; 20: 267-277.

20. Wyatt J, Dijk D, Ronda J, Jewett M, Powell J, Dinges D, et al. Interaction of circadian- and sleep/wake homeostaticprocesses modulate psychomotor vigilance test (PVT) performance. Sleep Res 1997; 26: 759.

21. Venker CC, Goodwin JL, Roe DJ, Kaemingk KL, Mulvaney S, Quan SF. Normative psychomotor vigilance task performance in children ages 6 to 11 - the Tucson Children's Assessment of Sleep Apnea (TuCASA). Sleep Breath 2007; 11: 217-224.

22. Bennett Murphy L, Caroline E, Rose CL. Sustained attention and unintentional injury among preschool-aged children. Child Neuropsychol 2001; 7: 72-83.

23. Thorne DR, Johnson DE, Redmond DP, Sing HC, Belenky G, Shapiro JM. The Walter Reed palm-held psychomotor vigilance test. Behav Res Methods 2005; 37: 111-118.

24. Adam JJ, Paas FG, Buekers MJ, Wuyts IJ, Spijkers WA, 
Wallmeyer P. Gender differences in choice reaction time: evidence for differential strategies. Ergonomics 1999; 42: 327-335.

25. Touitou Y, Portaluppi F, Smolensky MH, Rensing L. Ethical principles and standards for the conduct of human and animal biological rhythm research. Chronobiol Int 2004; 21 : 161-170.

26. Yang CM, Lin FW, Spielman AJ. A standard procedure enhances the correlation between subjective and objective measures of sleepiness. Sleep 2004; 27: 329-332.

27. Drummond SP, Bischoff-Grethe A, Dinges DF, Ayalon L, Mednick SC, Meloy MJ. The neural basis of the psychomotor vigilance task. Sleep 2005; 28: 1059-1068.

28. Frey DJ, Badia P, Wright KP Jr. Inter- and intra-individual variability in performance near the circadian nadir during sleep deprivation. J Sleep Res 2004; 13: 305-315.

29. Bell EC, Willson MC, Wilman AH, Dave S, Silverstone PH. Males and females differ in brain activation during cognitive tasks. Neuroimage 2006; 30: 529-538.

30. Sadeh A, Gruber R, Raviv A. The effects of sleep restriction and extension on school-age children: what a difference an hour makes. Child Dev 2003; 74: 444-455.

31. Randazzo AC, Muehlbach MJ, Schweitzer PK, Walsh JK. Cognitive function following acute sleep restriction in children ages 10-14. Sleep 1998; 21: 861-868.

32. Crowley S, Carskadon M. Circadian phase, sleepiness, mood, and vigilance changes after weekend "recovery" sleep schedules in teens: Preliminary results. Sleep Biol Rhythms 2007; 5: A7. 